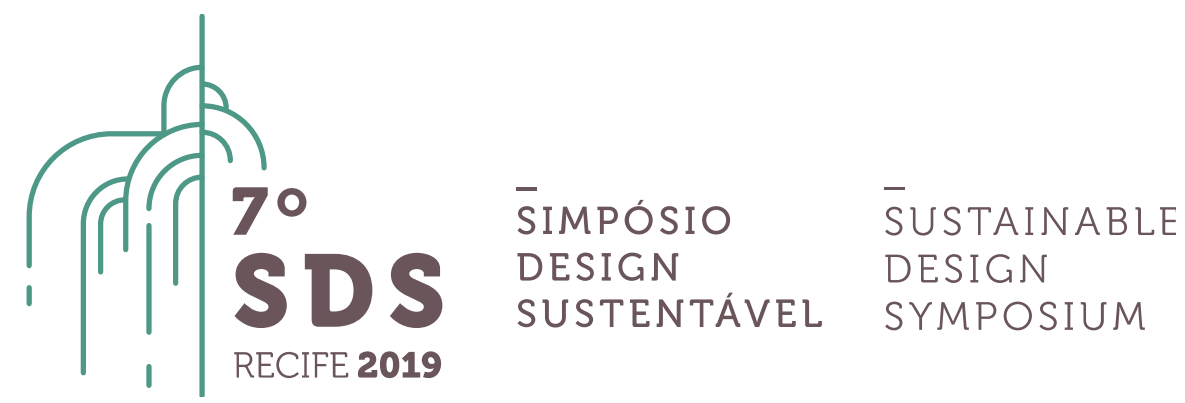

\title{
Dispositivos de gestão visual aplicados no Varal - Laboratório de Iniciativas em Design Social
}

\author{
Emilio Augusto Gomes de Oliveira ${ }^{1}$, Anna Lucia dos Santos Vieira e Silva ${ }^{2}$ \\ ${ }^{1}$ Universidade Federal do Ceará, Departamento de Arquitetura e Urbanismo e Design, emiliodesign@gmail.com \\ ${ }^{1}$ Universidade Federal do Ceará, Departamento de Arquitetura e Urbanismo e Design, lilu@dau.ufc.br
}

\begin{abstract}
Resumo. A pesquisa apresenta resultados da aplicação de dispositivos gráficos de gestão visual que buscam facilitar o entendimento da construção da identidade, visualização do método e operacionalização de projetos de design social do Varal - Laboratório de Iniciativas em Design Social da UFC. Os procedimentos metodológicos abordam uma revisão de literatura sobre os temas: gestão visual de projetos e design social cocriativo. Em relação aos resultados da pesquisa, são apresentados exemplos de aplicações destes dispositivos no âmbito da gestão de design estratégica, tática e operacional das ações do Laboratório. As considerações finais apresentam potencialidades e oportunidades para uso destes dispositivos visuais em projetos desta natureza ou em situações similares.
\end{abstract}

Palavras-chave. Design e gestão visual. Design social cocriativo. Dispositivos gráficos.

\section{Introdução}

Há um certo consenso que aspectos como informação e compreensão são fundamentais para qualquer organização, e, da mesma forma os processos devem ser fáceis de serem compreendidos e usados. Para Sibbet (2013), as pessoas gostam de interagir, e permitir que estas ponham suas mãos na informação, é um caminho direto para maior participação e engajamento. Assim, equipes podem se tornam mais eficientes e eficazes quando conseguem visualizar o tema ou o problema de forma que seja possível interagir comparando dados, localizando padrões e mapeando ideias, pois isso facilita a pensar de forma mais global (MEREDITH \& MANTEL, 2006; AMARAL et al, 2010; SIBEET,2013).

Normalmente, processos de desenvolvimento de projeto mais complexos, geralmente são de difícil compreensão e visualização. Isto ocorre em virtude de que implicam em muitas atividades, feitas por diferentes pessoas e equipes, cada uma delas produzindo resultados que, variavelmente, são utilizados em etapas subsequentes. Dessa forma, a complexidade pode aumentar em razão proporcional ao tamanho e especificidades de cada projeto (BROWNING, 2009; AMARAL et al, 2010). Portanto, a utilização de dispositivos gráficos na gestão visual de projetos que vise ampliar a visualização, documentação, controle e, da mesma forma, estimular a 
participação e a interação durante o processo projetual mostra-se importante. A partir desta premissa, a pesquisa tem como objetivo apresentar resultados da aplicação destes dispositivos no Varal - Laboratório de Iniciativas em Design Social da UFC.

Além da sua equipe interna, o Laboratório atua com diferentes públicos, muitos dos quais pessoas humildes e com baixo nível de letramento. Portanto, é fundamental que as informações sejam eficientes, de caráter mais visual e que possam facilitar o entendimento de forma clara e ampla.

\section{Metodologia}

A metodologia da pesquisa neste trabalho pode ser classificada conforme as definições clássicas citadas em Silva e Menezes (2001). Quanto à natureza, pode ser classificada como pesquisa aplicada, pois objetiva gerar conhecimentos para aplicação prática, no caso, o uso de dispositivos visuais na gestão de projetos, dirigidos à solução de problemas específicos, respectivamente nas ações do Varal.

A pesquisa é também classificada como bibliográfica, pois, buscou-se informações em publicações em livros e artigos e pode ainda ser caracterizada como uma análise teórica sistemática, pois visou identificar os estudos na área de gestão visual de projetos e design social cocriativo. Com essa revisão de literatura, buscaram-se referências que contribuíssem para a proposta dos presentes dispositivos gráficos a serem aplicados no Laboratório estudo de caso.

Segundo Lakatos e Marconi (2007), o estudo de caso refere-se ao levantamento com mais profundidade em dado caso ou grupo humano e não pode ser generalizado. Os autores também mencionam características relacionadas ao estudo de caso, as quais se alinham ao presente trabalho, em especial ao uso de dispositivos visuais, pois estes: (1) visam à descoberta; (2) enfatizam a interpretação do contexto; (3) retratam a realidade de forma ampla; (4) utilizam diversas fontes de informação; (5) permitem substituições; (6) representam diferentes pontos de vista em dada situação; e (7) fazem uso de linguagem simples. Portanto, a partir destas características, os dispositivos visuais foram utilizados, no Varal, em diferentes níveis de gestão de projetos, seja na esfera estratégica, tática e operacional, as quais serão ilustradas mais adiante no tópico de resultados de pesquisa.

\subsection{O estudo de caso: Varal}

O Varal - Laboratório de Iniciativas em Design Social é um espaço que envolve atividades de pesquisa, ensino e extensão na Universidade Federal do Ceará (UFC). Tem por objetivo atender demandas de comunidades em situação de vulnerabilidade econômica e social, por meio de ações e interações no campo do Design Social, com ênfase na construção de identidade local e regeneração urbana. Trabalhando com metodologias participativas e colaborativas, o laboratório identifica os problemas por meio de diagnósticos e propõe soluções em conjunto com as comunidades, no intuito de compartilhar experiências e conhecimentos de forma horizontal.

\section{Fundamentação teórica}

Para este trabalho, a pesquisa biliográfica foi realizada com base nos seguintes assuntos: gestão de projetos por meio de dispositivos visuais e design social cocriativo, respectivamente o campo do saber aplicado ao gerenciamento do Laboratório e o método de trabalho utilizado por este. 


\subsection{Dispositivos visuais para a gestão de projetos}

Em meio a um cenário de complexidade organizacional nos últimos anos, tem-se presenciado um aumento do número de técnicas e modelos voltados à simplificação de ideias e ações, de modo a apresentar uma visão integrada, eficiente e holística dos processos organizacionais vinculadas à gestão de projetos. Para Lester (2017), comunicar, implementar e monitorar dados de forma sistemática, organizada e de maneira disciplinar, tornam-se um desafio que podem ser facilitados com a utilização da visualização das informações e dos métodos visuais.

O Lean Institute Brasil (2009) define este tipo de gestão de projetos com ênfase no visual como um sistema de planejamento, controle e melhoria contínua que integra ferramentas simples, as quais possibilitam o entendimento e permitem, com uma rápida visualização, compreender a situação atual. Isso apoia o trabalho padronizado e a aderência dos processos e viabiliza melhorias, por exemplo.

Nesta visão, o uso sistemático de métodos visuais no planejamento estratégico, em especial, de projetos, possibilita uma variedade de práticas visuais para resolução de problemas (SINDIY et al., 2013). Diante deste contexto, os dispositivos e ferramentas visuais tipicamente incluem, imagens, vídeos, esboços, diagramas, quadros, painéis, infográficos, modelos, protótipos, dentre outros recursos interativos. Essas permitem aos envolvidos tornar a informação transparente e compreensível e auxiliar no foco dos processos, explicitando o que de fato é necessário (DUSSE et al., 2016). Para este trabalho, foi enfatizado o uso de diagramas, infográficos e painéis do tipo canvas.

O conceito de diagrama adquire diferentes sentidos e significados consoante as intenções e contextos em que é empregue. Proveniente do grego "diagramma", pelo latim "diagrama", a palavra diagrama traduz "traçado por linhas", ou na sua acepção corrente, "figura gráfica que representa um fenómeno determinado, um esquema visual. Segundo Séguier (2004) apud Simôes (2011), pode também expressar uma ideia ou conceito. Já a infografia é a apresentação impressa de um binômio imagem + texto, qualquer que seja o suporte onde se apresenta essa união informativa (DE PABLOS, 1999). Por sua vez, os quadros painéis do Business Model Canvas, propostos por Osterwalder e Pigneur (2011) são um mapa visual, como uma ferramenta dinâmica para criação, modificação, compreensão e inovação de modelos de negócios.

Atualmente, o gerenciamento visual de projetos é também um campo emergente de pesquisa que se preocupa com a construção de representações visuais de dados iniciais abstratos de forma a facilitar o seu entendimento e auxiliar na descoberta de informações (MARTINS JR., 2016). Desta forma, a visualização da informação permite que pessoas possam processar dado volume de informação, a partir de eficientes dispositivos de percepção visual, exigindo menor capacidade cognitiva cerebral (PATTERSON et al., 2014).

$\mathrm{Na}$ indústria, Greif (1991) descreve o gerenciamento visual como uma orientação da produção através de controles visuais, práticas de qualidade e organização do local de trabalho. Esse sistema visual objetiva, portanto, uma comunicação ativa através de controles que explicitem como determinadas atividades devem ser executadas de maneira ágil e organizada, identificando se há alguma inconsistência, erro ou desvio no processo para evitar futuras perdas produtivas.

No campo corporativo, Liff e Posey (2004), reforçam que o gerenciamento visual é um sistema de gestão que objetiva melhorar o desempenho organizacional através da conexão e do alinhamento da visão, dos valores, dos objetivos e da cultura de uma empresa, por meio de estímulos sensoriais. Dentre os principais benefícios, constam a melhor exposição das informações 
necessárias e a facilidade de assimilação dessas informações corporativas (MESTRE et al., 2000). Ainda neste ambiente, Greif (1991) defende a gestão visual de projetos como uma forma poderosa de fazer a informação fluir rápida e eficazmente dentro da empresa, alinhando os esforços de todos os colaboradores com os objetivos e estratégias globais da empresa.

Além do contexto da pesquisa, da produção fabril e da abordagem corporativa, nas referências bibliográficas foram encontradas diferentes percepções e abordagens relacionadas ao uso de dispositivos visuais, principalmente no campo da gestão de projetos (TEIXEIRA, 2018). Eppler e Platts (2009) também apontam a importância estratégica do uso de painéis e demais ferramentas visuais para facilitar a percepção de padrões, status projetual e outras informações pela equipe de projeto. Além destas, as formas de apresentação visuais são ilimitadas, pois os recursos gráficos são guiados apenas pelo objetivo de tornar fáceis e acessíveis as orientações, os procedimentos, processos e a comparação do desempenho real versus o esperado. Um dos benefícios complementares das apresentações visuais, conforme Eppler e Platts (2009) é que elas podem ser evocativas e, portanto, inspiradoras, interativas e cativantes.

Do ponto de vista histórico, a origem da gestão visual de projetos está associada a adoção de métodos enxutos, inerentes à abordagem Lean, iniciada nos anos 1940, em meio ao desenvolvimento da indústria automotiva japonesa, mais especificamente na Toyota (PARRY \& TURNER, 2006). Seu objetivo era reduzir custos, aperfeiçoar o sistema produtivo, promover uma melhoria contínua dos processos de produção e eliminar perdas que não agregam valor (JACA et al., 2014). A gestão visual de projetos pode ser considerada como um dos elementos fundamentais da abordagem Lean (TEZEL et al., 2015; IMAI, 1990).

Outra característica importante da gestão visual de projetos é a possibilidade da comunicação universal, na qual até mesmo pessoas externas ao processo podem compreender as informações, conseguir visualizar e entender o que está acontecendo em qualquer componente ou etapa do processo (SANTOS, 1999).

\subsection{Design social cocriativo}

Segundo Victor Margolin (2004) o principal objetivo do design social é corresponder às necessidades humanas e o contexto em que ocorrem e demanda uma visão ampla de conceitos como sustentabilidade. Para Krippendorf (2000) 'o entendimento necessário ao design para e com stakeholders (público estratégico) é um entendimento não somente da tecnologia envolvida, mas, antes, do que a tecnologia significa para as pessoas'. Neste sentido, o Varal é guiado pelo comprometimento com a coerência interna e pró-atividade, mostrando-se sempre acessível tanto para novos projetos quanto novos parceiros. Para tal os projetos possuem um prazo médio de dois anos e são sedimentados em áreas de atuação menores que dialogam entre si, permitindo maior dinâmica nas ações. Desde sua criação, em 2012, houve um crescimento de demandas, equipes e complexidade.

O laboratório entende que o design social opera em situações de vulnerabilidade econômica em um processo estratégico, participativo e horizontal onde todos os envolvidos são co-responsáveis por uma transformação social, local e ativa. O objetivo, além de atender as demandas da comunidade, é de envolvê-la totalmente no projeto, de forma que o design não seja intervencionista nem assistencialista, e sim cocriativo. No sentido de sintetizar visualmente e sistemicamente o conceito do design social, a equipe do Varal desenvolveu o seguinte diagrama (fig. 1): 
Figura 1 - Diagrama sistêmico conceitual sobre design social.

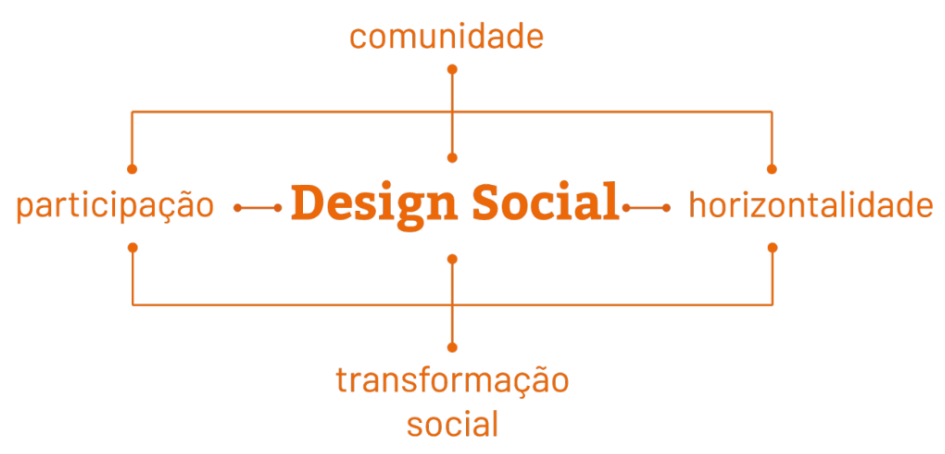

Fonte: Pesquisa direta

As propostas do laboratório promovem iniciativas em design social, que tratam de situações locais e de pessoas, com hábitos e empenho, no enfrentamento do cotidiano. Proposições colaborativas implicam na produção de um tipo de redescoberta dessas pessoas de seu próprio potencial e capacidade de resolver problemas. O design entra como um meio capaz de facilitar novas organizações e pontos de vista da comunidade em relação a si mesma. Manzini (2017, p.17) atribui aos especialistas em design uma parte ativa nessa redescoberta, pois são: "promotores da mudança social, uma vez que colaboram ativamente na criação das condições que a facilitam."

Os desdobramentos do design como discurso associam-se à noção de Design Centrado no Ser Humano. Os projetos realizados não somente trazem os usuários e comunidades como forças participativas, mas também guardam suas vontades e desejos como bússolas projetuais, almejando sempre entender e colocar as vontades dos moradores em primeiro lugar. O HumanCentered Design ( $\mathrm{HCD}$, ou Design Centrado no Ser Humano), como trazido pelo Field Guide to Human-Centered Design (IDEO, 2009, p.5), traz noções básicas sobre o que é e como utilizar o HCD em campo. Além de "Human-Centered Design", a sigla HCD também evoca três conceitos importantes desta ferramenta: Hear (Ouvir), Create (Criar) e Deliver (Implementar): "A razão pela qual esse processo é chamado de 'Centrado no Ser Humano' é que ele começa pelas pessoas para as quais estejamos criando a solução."

\footnotetext{
"O design é uma cultura e uma prática relativas ao modo como as coisas deveriam ser a fim de alcançar as funções e os sentidos desejados. Ele tem lugar em processos abertos de codesign, nos quais todos os atores envolvidos participam de diferentes maneiras." (Manzini, 2017, p. 68)
}

No processo de codesign (Manzini, 2017) o sentido de cocriação e de cooperação no processo de projeto abrange três tipos de premissas: 1- "processos altamente dinâmicos" como metodologias de construção de consenso e processos complexos interconectados, frequentemente contraditórios; 2- "atividades criativas e proativas" que abrangem iniciativas dos participantes e a criatividade como propulsora de diálogos sociais alimentados por novas ideias; 3"atividades complexas de design" que demandam ferramentas específicas de design para tornar situações e ideias complexas tangíveis e comunicáveis (MANZINI, 2017).

Portanto, a partir deste referencial teórico, os dispositivos de gestão visual são apresentados a seguir com exemplos em cada um no escopo da aplicação da gestão de design do Varal, sendo utilizado os três níveis de tomada de decisão apresentados por Mozota (2011): 
- O nível estratégico, ou o papel do design para unificar e transformar a visão da empresa, pode designar a gestão de uma empresa de acordo com princípios e estratégias de design;

- O nível tático (funcional), ou a criação de uma função de design na empresa pode referirse a administração de um departamento de design (ou mesmo de uma empresa de design);

- O nível operacional, o primeiro passo para a integração do design e pode referir-se a gestão de um projeto de Design.

\section{Resultados}

\subsection{Dispositivos de gestão visual: nível estratégico}

Em nível estratégico, faz-se necessário o reconhecimento e definição da identidade do laboratório, enquanto organização, a fim de que o público interno e externo possa ter consciência da profundidade de suas ações e missões, através da construção da sua plataforma de marca. Então, com base no diagnóstico de marca, a construção e definição da sua estratégia e posicionamento, faz-se necessário consolidar o planejamento através de uma plataforma de marca, ou seja, a declaração estratégica ou conjunto de afirmações ou de itens preliminarmente definidos, que: englobam aquilo que a marca é ou será; aquilo que a marca faz ou fará; como é que pretende ter sucesso; e porque ela é ou será única, diferente ou singular. Algo que clarifica as comunicações internas e alinha todos os colaboradores para irem na direção dos mesmos propósitos (NASCIMENTO, 2011).

Trata-se, portanto de uma síntese de todas as informações levantadas e discutidas sobre a organização e, por conseguinte, a identidade da marca. O autor pontua ainda que, embora as plataformas de marca variem de empresa para empresa, de especialista para especialista, a maioria delas deve ser constituída por vários elementos que irão compor a sua identidade, dentre os seguintes: origem e história da marca; posicionamento da marca; modelo de gestão em branding; caráter ou personalidade da marca; promessa da marca; propósito de marca; missão da marca; visão da marca; valores da marca; essência da marca.

Finalmente, a plataforma de marca deve ser facilmente identificada pelo cliente e também por sua equipe interna, a qual deve estar alinhada aos valores propostos para agir e representar a essência da marca e sua razão de ser, de acordo com o seu posicionamento em qualquer ponto de contato. No intuito de sintetizar visualmente este processo, o presente trabalho também propõe o uso de uma ferramenta visual denominada Brand Key, desenvolvida pelo Laboraório. Trata-se de uma metáfora/analogia visual a qual a chave do processo de branding é definir a plataforma marcaria através de 10 blocos constitutivos, inspirados no Business Model Canvas.

Na ponta da chave, o início do processo, existe os 3 primeiros blocos referentes à síntese do diagnóstico de marca, a definição do seu posicionamento e o conceito e modelo de gestão de branding a ser trabalhado, os quais consistem na estratégia da marca. A parte da pega/apoio da chave consiste na definição do DNA, ou seja, o conjunto de 7 blocos constitutivos composto pela personalidade, promessa e propósito que, respectivamente, se associam à missão, visão e valores em um nível mais aprofundado de definição (ou metaforicamente, o giro da chave) até a síntese da essência da marca, ao centro destas formas circulares concêntricas. Especificamente, a ferramenta Brand Key foi utilizada no Varal durante a etapa de diagnóstico e planejamento da gestão de marca (branding) do Laboratório, mediante reuniões entre os stakeholders internos e externos. 0 resultado está sintetizado na figura 2: 


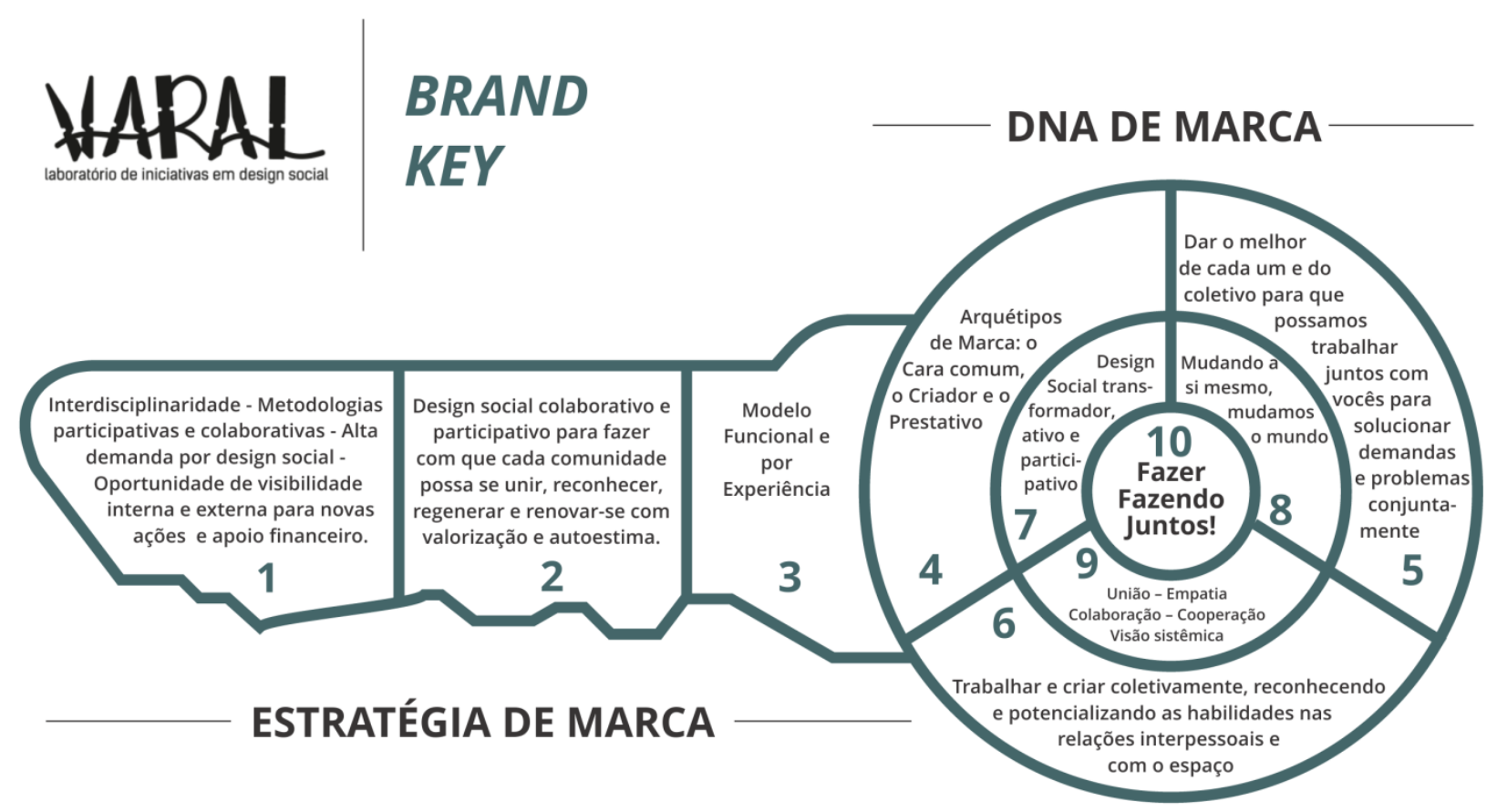

1. Análise SWOT
3. Modelo de Gestão de

5. Promessa da marca

6. Propósito da marca
2. Posicionamento

\section{Missão}

8. Visão branding

\section{Personalidade} da marca

9. Valores

10. Essência

Fonte: Pesquisa direta

\subsection{Dispositivos de gestão visual: nível tático}

O dispositivo selecionado para exemplificar o nível tático da gestão visual do Varal é o infográfico, da mesma forma utilizado como ferramenta de entendimento da metodologia de ação do Laboratório. Inspirada no método HCD, o 3Cs também apresenta três fases subsequentes: conhecer, criar (juntos) e concretizar. Semanticamente é uma metáfora visual com o ser humano, ou seja, o conjunto cabeça, corpo e coração.

A primeira etapa é a cabeça: olhos, ouvidos e pensamento no ato de acolher, receber, observar, conhecer e conectar. É o momento de verificar as demandas trazidas ao laboratório por representantes de uma comunidade que possui algum problema. É importante que a conexão ocorra por meio de imersões na situação, mapeamentos, entrevistas, registros fotográficos, vídeos e toda sorte de informações que auxiliem a identificação dos problemas na comunidade.

Nesta etapa também são formadas parcerias, fundamentais para a proposição e execução de ações das etapas posteriores. Após consolidado o diagnóstico, é definido o problema de projeto a partir da compreensão das demandas apresentadas e dos dados coletados. Caso necessário, são construídas novas demandas, de acordo com a observação reflexiva sobre o problema que, uma vez definido, pode apontar para a formulação de novas questões. Compartilhar com os parceiros os resultados coletados e a apresentação à comunidade é o final desta etapa, pois o reconhecimento de seus próprios problemas é fundamental para que as 
transformações sejam duradouras.

A segunda etapa é "mão na massa", é com o corpo que se cria juntos. Esta fase marca o início do processo participativo de projeto onde se busca, de forma cocriativa, solucionar os problemas que foram identificados na primeira etapa. Quando oportuno e possível, ocorre a participação de demais estudantes das disciplinas que focam na temática do Design Social no curso de Design da Universidade Federal do Ceará. Os estudantes apresentam protótipos, sistemas de soluções e proposições, as quais são denominadas de dispositivos estratégicos de design social. É o Design como um meio para um objetivo que está muito além dele. Os dispositivos são testados, aprimorados e implementados a fim de fomentar o sentido de pertencimento dentro da comunidade e aumentar a sua visibilidade na cidade ou para instituições que também possam colaborar de maneira positiva no processo. Quando necessário as soluções são recriadas até que alcancem os objetivos específicos das demandas, por meio da pesquisa ação.

Na terceira etapa, concretiza-se, analisa-se o processo e os resultados são entregues, com a geração de valor, bem-estar e melhorias sendo visualmente representado pelo ícone coração. Tem-se a percepção de que o projeto é bem sucedido quando os resultados são a emancipação, autonomia, desejo de transformação e continuidade das ações por parte da própria comunidade. A seguir, o infográfico (fig. 3), que representa visualmente o método 3 Cs do Varal. A fase conhecer, mais ampla e circular; a fase criar juntos, em processo de definição figurativa e em desenvolvimento; e o concretizar, já com o símbolo figurativo do coração.

Figura 3-Metodologia 3Cs do Varal.
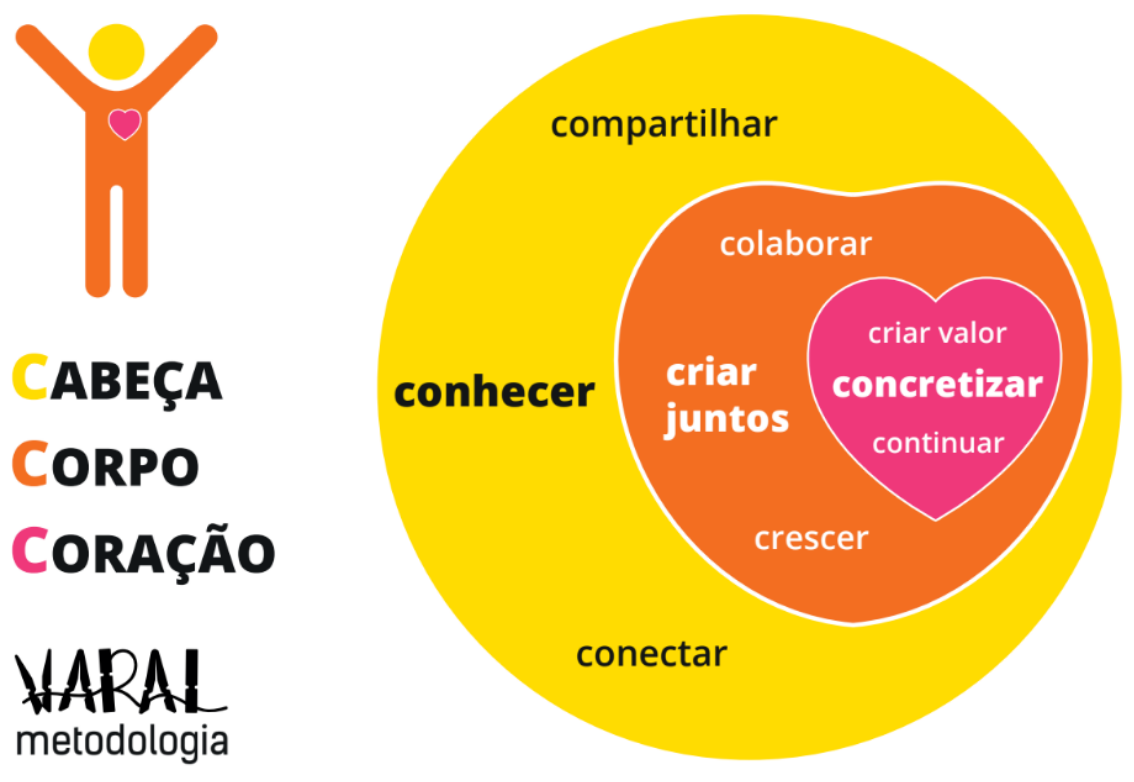

Fonte: Pesquisa direta 


\subsection{Dispositivos de gestão visual: nível operacional}

Do ponto de vista operacional, o uso de diagramas, tem se mostrado uma ferramenta eficiente de entendimento, principalmente na tomada de decisão, dignóstico e apresentação de dados para diferentes públicos. Pode-se exemplificar o diagrama da cadeia produtiva de artefatos em barro (fig. 4), desenvolvidos pelos artesãos em Moita Redonda, Cascavel-CE, uma das comunidades atendidas pelo Varal. No diagrama, pode-se entender, de forma clara, o fluxo de produção desde a extração de matéria-prima até o processo de venda:

Figura 4 - Diagrama da cadeia produtiva em Moita Redonda.

\section{Cadeia Produtiva}

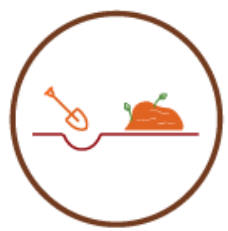

1. Extração

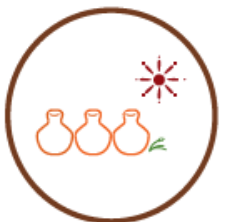

5. Secagem

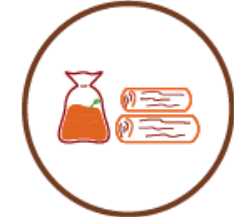

2. Aquisição de matéria-prima

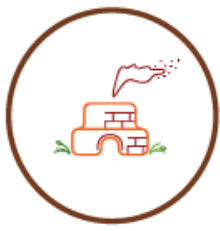

6. Queima

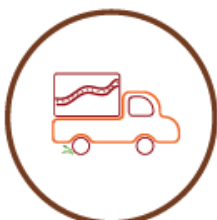

9. Transporte

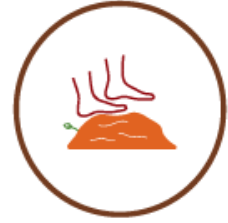

3. Preparação do barro

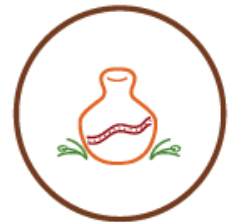

7. Pintura

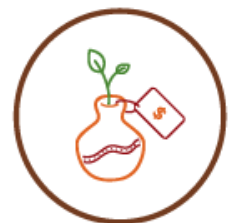

10. Venda

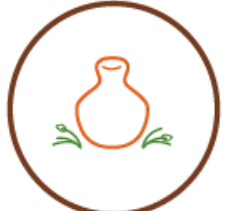

4. Modelagem

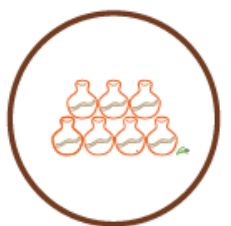

8. Estocagem

Fonte: Pesquisa direta

\section{Considerações finais}

A pesquisa apresentou a utilização de dispositivos de gestão visual no Varal - Laboratório de Inciativas em Design Social da UFC. Além de facilitar o processo de gestão do design, em especial na construção de identidades, acredita-se que a ampliação do uso destes dispositivos visuais podem facilitar a integração e o fluxo de informações entre as etapas de projeto, trazendo mais agilidade ao processo. Como são ferramentas comuns já apropriadas na seara de métodos utilizados por designers especialistas, faz necessário aprimorá-las para um alcance mais amplo e interativo, por parte do público externo, em especial naquelas comunidades em situação de vulnerabilidade e não tão acostumadas com o uso destes dispositivos no seu cotidiano, o que poderia ser um fator limitante. Ressalta-se, por fim, que o uso de destes dispositivos é uma abordagem com grande potencial estratégico, tático e operacional e seus princípios podem ser adaptados para outras metodologias de desenvolvimento de projetos e gestão em geral. 


\section{Referências}

AMARAL, D. et al. Gestão de desenvolvimento de produtos: uma referência para a melhoria do processo. São Paulo: Saraiva, 2010.

BROWNING, T. R. The many views of a process: toward a process architecture framework for product development processes. Systems Engineering, v.12, n.1, p.69---90, 2009.

CLARK, T. Business model you: o modelo de negócios pessoal - o método para reinventar sua carreira. Rio de Janeiro: Alta Books, 2013.

DE PABLOS, J. M. Infoperiodismo: el periodista como creador de infografia. Madrid: Editorial Sintesis, 1999.

DUSSE, F., Jr., P. S.; ALVES, A. T.; NOVAIS, R.; VIEIRA, V.; MENDONÇA, M. Information visualization for emergency management: a systematic mapping study. Expert Systems with Applications, 45(1), 424-437. 2016.

EPPLER, M.; PLATTS, K. Visual strategizing: the systematic use of visualization in the strategicplanning process. Long Range Planning, 42(1):42-74. Disponível em: http://www.sciencedirect.com. Acesso em: 27/04/2019.

GREIF, M. The visual factory: building participation through shared information. Portland, EUA: Productivity Press, 1991.

IDEO. HCD - Human Centered Design: Kit de ferramentas. EUA: Ideo, 2009. 102 p. Disponível em: <http://www.ideo.com/work/human-centered-design-toolkit/>. Acesso em: 28/04/2019.

IMAI, M. Kaizen: a estratégia para o sucesso competitivo. São Paulo: Instituto de Movimentação e Armazenagem de Materiais - IMAM, 1990.

JACA, C.; VILES, E.; JURBURG, D.; TANCO, M. Do companies with greater deployment of participation systems use Visual Management more extensively? An exploratory study. International Journal of Production Research, 52(6), 1755-1770. 2014.

KRIPPENDORFF, K. 2000. Design Centrado no Ser-humano = Human-centered Design: uma necessidade cultural = a cultural necessity. Estudos em Design, Rio de janeiro, v.8, n.3.

LEAN INSTITUTE BRASIL. 2009. Gestão visual para apoiar o trabalho padrão das lideranças. Disponível em: http:// www.lean.org.br. Acesso em: 27/04/2019.

LESTER, A. Project management, planning and control: managing engineering, construction and manufacturing projects to PMI, APM and BSI standards. Cambridge: Elsevier, 2017.

LIFF, S.; POSEY, P. A. Seeing is believing: how the new art of visual management can boost performance throughout your organization. Nova York, EUA: Amacom, 2004.

MANZINI, E. Design: quando todos fazem design - uma introdução ao design para inovação social. São Leopoldo RS: Ed. Unisinos, 2017.

MARCONI, M.A; LAKATOS, E. Metodologia Científica. São Paulo: Atlas, 2007.

MARGOLIN, V. e MARGOLIN, S. 2004. Um "modelo social” de design: questões de prática e pesquisa; in Revista Design em Foco, UEB.

MARTINS JR., S. L. Efetividade do gerenciamento de projetos utilizando ferramentas da Web 2.0 e gestão do conhecimento. Projetos e Dissertações em Sistemas de Informação e Gestão do Conhecimento, 4(2), 2016.

MEREDITH, J.R. e MANTEL, S.J. Project management. New York: Wiley, 2006. 
MESTRE, M.; STEINER, A.; STAINER, L.; STROM, B. Visual communications: the Japanese experience. Corporate Communications: An International Journal, 2000. v. 5, Iss 1 p. 34-41

MOZOTA, B. Gestão do design: usando o design para construir valor de marca e inovação corporativa. Porto Alegre : Bookman, 2011.

NASCIMENTO, A. Branding: plataforma de marca é uma ferramenta de gestão que faz a diferença> Disponível em: http://www.estrategiaebranding.com.br/branding-plataforma-de-marca-e-umaferramenta-de-gestao-que-faz-diferenca/. Acesso em 29 abril 2019.

OSTERWALDER, A.; PIGNEUR, Y. Business Model Generation: inovação em modelos de negócios: um manual para visionários, inovadores e revolucionários. Alta Books, 2011.

PARRY, G. C.; TURNER, C. E. Application of lean visual process management tools. Production Planning \& Control, 17(1), 2006.

PATTERSON, R. E.; BLAHA, L. M.; GRINSTEIN, G. G.; LIGGETT, K. K.; KAVENEY, D. E., SHELDON, K. C.; MOORE, J. A. (2014). A human cognition framework for information visualization. Computers \& Graphics, 42 (Special), 42-58.

SANTOS, A. (1999). Application of flow principles in the production management of constructions sites. Tese de doutorado, University of Salford, Salford, Grande Manchester, Reino Unido.

SIBBET, D. Reuniões visuais: como gráficos, lembretes autoadesivos e mapeamento de ideias podem transformar a produtividade de um grupo. Rio de Janeiro: Alta Books, 2013.

SILVA, E. L. da; MENEZES, E. M. Metodologia da pesquisa e elaboração de dissertação. Florianópolis, 2011.

SIMÕES, P. J. A. (2011). Didática de metodologias para a facilidade de uso: design de diagramas e sua representação visual. Disponível em: http://repositorio.ul.pt/handle/10451/6611. Acesso em 29 abr 2019.

SINDIY, O.; LITOMISKY, K.; DAVIDOFF, S.; DEKENS, F. Introduction to information visualization (infovis) techniques for model-based systems engineering. Procedia Computer Science, 16(1), 4958. 2013.

TEIXEIRA, J. M. Gestão visual de projetos: utilizando a informação para inovar. Rio de Janeiro: Alta Books, 2018.

TEZEL, A.; KOSKELA, L.; TZORTZOPOULOS, P.; FORMOSO, C. T.; ALVES, T. Visual management in Brazilian construction companies: taxonomy and guidelines for implementation. Journal of Management in Engineering, 31(6). 2015. 